\title{
MOMENTOS DE REFLEXÃO DOCENTE FRENTE À SOCIEDADE DA INFORMAÇÃO: INVENTIVIDADE E PRODUÇÃO DE SUBJETIVIDADES
}

\section{Teacher Reflection Moments due to the Information Society: Inventivity and Production of Subjectivities}

\author{
Francieli Motter Ludovico* \\ Patrícia da Silva Campelo Costa Barcellos**
}

\begin{abstract}
Resumo: A escola moderna foi constituída com a intenção de adestrar e controlar os indivíduos. Dessa forma, o objetivo do presente trabalho é mostrar a necessidade da mudança de tais práticas e promover reflexões acerca da formação docente que caminhem nessa direção. Essa pesquisa teórica também busca refletir sobre as mudanças provocadas pela Tecnologia de Comunicação Digital, dado que o modo como esses recursos são utilizados pode possibilitar desenvolvimento ou perpetuar a transmissão do conhecimento e a reprodução de discursos dominantes. Para que práticas inventivas façam parte da educação e, assim, existam oportunidades para a singularização, a mudança pode iniciar pela formação de professores.
\end{abstract}

Palavras-chave: Formação de professores. Tecnologias de Comunicação Digital. Singularização. Educação.

Abstract: The modern school was formed with the intention of training and controlling the individuals. Thus, the objective of the present work is to show the need to change such practices and to promote reflections on teacher education that move in this direction. This theoretical research also seeks to reflect on the changes brought by Digital Communication Technology, given that the way these resources are used can enable development or perpetuate the knowledge transmission and the dominant discourses reproduction. For inventive practices to be part of education and thus opportunities for singularization to exist, change can begin with teacher education.

Keywords: Teacher training. Digital Communication Technologies. Singularization. Education.

\footnotetext{
* Doutoranda em Informática na Educação na Universidade Federal do Rio Grande do Sul - UFRGS; Mestre em Letras; Graduada em Letras Licenciatura- Português/Inglês. Professora da Universidade Tecnológica Federal do Paraná - UTFPR - Campus Dois Vizinhos. Ordcid: https://orcid.org/0000-0002-7655-497X. E-mail: franludovico@hotmail.com.

** Doutora em Informática da Educação e em Linguística Aplicada; Mestre em Letras; Graduada em Letras Licenciatura- Português/ Inglês. Professora do Programa de Pós-Graduação em Informática na Educação e do Instituto de Letras - Universidade Federal do Rio Grande do Sul - UFRGS. Orcid: https://orcid.org/0000-00025142-4730. E-mail: patrícia.campelo@ufrgs.br.
} 


\section{Introdução}

Além de educar e formar, a concepção da escola como instituição deriva do propósito de dar forma, ou seja, moldar os estudantes. Nessa mesma direção, os professores foram formados para serem detentores do saber, indivíduos de autoridade, a fim de serem capazes de controlar seus alunos e também seu aprendizado. Apesar de grandes mudanças desde sua criação, essencialmente, muitas práticas permanecem iguais.

Diante da sociedade da informação onde 'verdades' são proclamadas a todo instante, esses discursos influenciam e transformam opiniões, que consequentemente, modificam comportamentos. Coll e Monereo (2010, p.20) definem sociedade da informação como "um novo estágio de desenvolvimento das sociedades humanas, caracterizado, do ponto de vista das TIC1, pela capacidade de seus membros para obter e compartilhar qualquer quantidade de informação de maneira praticamente instantânea", de qualquer lugar e de inúmeras maneiras.

Essa avalanche de informações está disponível e reproduzindo subjetividades discursos. Logo, torna-se extremamente necessário ter discernimento para confrontar as informações e não ser manipulado pelos discursos dominantes plantados, inseridos com um propósito, não raras vezes, ocultos ou mascarados diante de informações divulgadas por fontes que nem sempre possuem credibilidade.

Hoje as práticas escolares são reconhecidas por constituírem-se, principalmente, por Políticas Recognitivas, por meio de representação, e, dessa maneira, há a necessidade de abrir espaço para o desenvolvimento de Políticas Inventivas. Ou seja, caminha-se em busca de uma escola que ofereça "um espaço privilegiado para os muitos jogos sociais; o jogo instaura o espaço da liberdade, da diferença e do diálogo" (CARRANO, 2005, p.156).

Isso posto, o objetivo deste estudo é justificar a necessidade da mudança da escola moderna e promover reflexões acerca da formação de professores para que a transformação dessa seja possível. Espera-se uma formação que proporcione momentos de reflexão docente, oportunizando questionar subjetividades, verdades dadas, oferecendo espaço para que o professor possa ser inventivo, (re)produza outras subjetividades e, quiçá, singularize-se reflita e se reaproprie de um discurso.

O presente trabalho inicia discorrendo acerca da constituição da instituição escola na modernidade e suas principais características. Em seguida, a mudança da escola moderna é discutida e, para isso, considera-se essencial investir esforços no âmbito da formação de professores. Evidencia-se a importância de práticas docentes que permitam a (re)produção de outras subjetividades, visando oportunidades para singularização de todos os envolvidos nos processos de ensino e de aprendizagem.

\section{A Escola Moderna}

A revolução industrial trouxe novas técnicas de produção, novas tecnologias, novas maneiras de organizar o trabalho e, com isso, o advento do capitalismo. Com a ciência moderna veio o abandono do pensamento místico e religioso, e as 'grandes descobertas' mudaram a vida. Essas novas configurações marcaram o início da modernidade.

\footnotetext{
${ }^{1}$ Os autores utilizam a sigla TIC para fazer referência às Tecnologias de Informação e Comunicação. Neste trabalho o termo utilizado é TCD - Tecnologia de Comunicação Digital, de autoria de Catapan (2001, p.3), e "refere-se às novas formas de informação e comunicação com base na linguagem digital".
} 
O poder disciplinador da era moderna tinha como forma de dominação a biopolítica2: Fazer viver, deixar morrer (FOUCAULT, 1999). Fazer viver do jeito que deve ser, e deixar morrer aqueles que não se adequam. É com o objetivo de normatizar, criar regras e regulamentos para organizar a sociedade que o estado cria as instituições: escola, fábrica, banco, família, polícia, presídios, justiça, hospital, hospício, exército, entre outras.

A primeira definição de escola, no dicionário Aurélio3, e provavelmente a mais comum é: 'Estabelecimento de ensino', no entanto, "a escola surge não apenas para ensinar saberes, mas fundamentalmente para adaptar e sujeitar os corpos dos trabalhadores da modernidade industrial capitalista" (CARRANO, 2005, p.155).

As instituições disciplinares funcionaram como observatórios, com o intuito de fabricar indivíduos adequados. Foucault (2009) salienta que é possível perceber essa intenção até na arquitetura das instituições, que não foram pensadas para dar conforto, beleza ou proteção, mas para controlar as pessoas que estão no interior, com o objetivo de vigiar, transformar e modificar esses indivíduos.

As instituições criam uma 'normalização', definem um padrão, quem não é capaz de segui-lo é punido. Na escola, para averiguar esse padrão existe o exame, por exemplo, ritual de poder que "é um controle normalizante, uma vigilância que permite qualificar, classificar e punir. Estabelece sobre os indivíduos uma visibilidade através da qual eles são diferenciados e sancionados" (FOUCAULT, 2009, p.209). Recuperação, repetição e reprovação são outras formas de punição. Nessa concepção, o problema é o próprio indivíduo, ele que não tem capacidade e acredita que é responsável pelo seu fracasso ou sucesso e, por isso, não questiona o funcionamento.

Zambel e Lastória (2016) trazem as ideias de Adorno e explicam que a escola deveria ser produtora de consciência verdadeira, permitir o desenvolvimento de autonomia, o livre pensar, a emancipação, no entanto, ela funciona "como reprodutora do sistema vigente; como instrumento de massificação e manipulação, mas não como produtora de uma consciência verdadeira" (ZAMBEL; LASTÓRIA, 2016, p.2210-2211).

As instituições, geridas pelo estado moderno, modulam a forma de viver e a subjetividade de todos, treinam o indivíduo, como ele deve perceber o mundo, o outro e a si mesmo. Tudo que é dito não se refere apenas a ideias, mas "sistemas de conexão direta entre as grandes máquinas produtivas, as grandes máquinas de controle social, e as instâncias psíquicas que definem a maneira de perceber o mundo" (GUATTARI; ROLNIK, 2010, p.27).

A escola moderna reproduz os discursos, subjetividades, como verdades e modela seu público, sendo o professor o detentor do saber e não existindo momento para reflexão ou discussão, mas conhecimento para ser transmitido e adquirido.

Mascarenhas (2018, p.1540) afirma ser necessário ir além do diagnóstico, atravessar a condição da escola no que se refere ao presente estudo, "com problematizações que possam abrir novas possibilidades de construção da existência". Nesse sentido, surgem questionamentos que podem conduzir à reflexão acerca do assunto, afinal de contas, o que é normal? Não existe espaço para a reflexão dentro da escola? Os alunos são todos iguais? Exame como sanção normalizadora? O sucesso e insucesso do aluno é de sua inteira responsabilidade? Escola para adestrar? Que escola é essa?

\footnotetext{
2 Biopolítica ou Biopoder termos utilizados por Foucault (1999) para nomear um conjunto de práticas utilizado para controlar a vida.

${ }^{3}$ https://dicionariodoaurelio.com/escola
} 


\section{3 (Re)Produção de Subjetividades e Singularização}

Fazendo uma breve reflexão, é possível perceber que muitas dessas características advindas da escola moderna estão presentes ainda hoje, e devido à sua solidez histórica é evidente que não será fácil desconstruí-la. No entanto, é incontestável a necessidade de romper com essas práticas limitadoras para possibilitar a singularização e a (re)produção de outras subjetividades, em outras palavras, para o desenvolvimento da sociedade.

Carrano (2005, p.160) afirma que a escola tem evoluído em certos aspectos, mas destaca que "ainda precisamos avançar muito no sentido da extensão do direito à pluralidade aos próprios jovens que, em muitas circunstâncias, são tratados como uma massa uniforme de alunos sem identidade".

A escola, os professores, os estudantes, todos reproduzem subjetividades, é fato, e isso sempre vai acontecer; a grande questão é como se lida com elas. Guattari e Rolink (2010) explicam que a maneira pela qual essa subjetividade é vivida alterna entre dois extremos, ou de alienação de opressão, quando o indivíduo assume a subjetividade do jeito que a recebe, ou, de expressão e criação, onde o indivíduo se reapropria dos elementos da subjetividade, proporcionando, assim, um processo de singularização.

A escola deve ser o espaço que permita o questionamento das 'verdades', a discussão e reflexão das subjetividades dadas, para (re)produzir outras subjetividades e ter a oportunidade de singularização, a qual é particular, mas só é possível em contato com o exterior. Guattari e Rolink (2010, p.37) salientam que "o processo de singularização da subjetividade se faz emprestando, associando, aglomerando dimensões de diferentes espécies".

O professor é um ator de prestígio no cenário da escola, é ele que poderá suscitar os momentos de reflexão, porém, para tanto, ele não pode reforçar os discursos dominantes, mas trabalhar a favor do processo de singularização na medida que for possível (GUATTARI; ROLNIK, 2010). Ou seja, o professor deve aproveitar sua posição dentro da sala de aula para provocar o (re)pensar, o expressar, para, em primeiro lugar, ensinar o refletir sobre as verdades dadas.

Logo, para que a transformação da escola seja possível, a mudança no papel do professor é um aspecto primordial. Se o professor, ele mesmo, não for capaz de questionar subjetividades, de se singularizar, também não poderá ensinar essas práticas aos seus estudantes. Por isso, ele tem o compromisso de estar em constante processo de singularização, estar disposto a mudar, refletir e aprender com suas práticas e estudantes.

O papel de único detentor do conhecimento já não convém, e Corazza (2008, p.92) explica que "tradicionalmente, a palavra docente nos reporta a um indivíduo constituído, já pronto". A compreensão do professor como ser formado, completo, sem necessidade de aperfeiçoamento e fechado a novos aprendizados, exclui as possibilidades de singularização.

O professor, de qualquer maneira, irá reproduzir subjetividades, mas ele pode optar por outras, que não as dominantes, mostrando que existem outras possibilidades, interpretações e, assim, provocar reflexões e discussões que oportunizem a singularização dos estudantes. Afinal, "o que torna a aprendizagem humana singular não é a assimilação direta da realidade, mas o contato e a troca com outras consciências e sensibilidades" (CARRANO, 2005, p.156). Esse autor ainda explica que a escola é reconhecida como o lugar de aprender, no entanto, ela também deveria ser um espaço para desaprender, questionar os condicionamentos sociais que nos distanciam da autoconsciência. Questionar permite refletir e conhecer. 
O professor tem o desafio de mostrar que é importante ser questionador, ser crítico, e provocar a reflexão no sentido de indicar que nem tudo o que é dito (ou publicado em redes sociais, por exemplo) é verdade, para que dessa maneira, os estudantes possam desenvolver novas competências e permitam-se mudar. No atual contexto, onde a informação está presente a um clique de quem a busca, o antigo papel atribuído ao docente como detentor de "informações" ou de "dados" para reprodução (educação bancária) não tem - não pode ter mais espaço. Não se pode crer em tudo que está exposto e em tudo que é dito. Com o avanço tecnológico, as barreiras espaço-temporais foram rompidas e afirmações de todo o tipo (verdadeiras ou falsas) estão em toda a parte e, muitas vezes, são disseminadas sem reflexão ou análise crítica acerca de seu teor ou veracidade. Facilmente, a consulta a enciclopédias ou bibliografias, até mesmo estudos científicos, são substituídos por referências de redes sociais ou notícias publicadas por meios de comunicação tendenciosos.

A transformação da informação em conhecimento subentende um processo pessoal, oriunda de processos de singularização por parte de cada sujeito. O saber é uma síntese humana. O professor, portanto, é detentor do SEU saber, do que ele conseguiu construir a partir de SEUS processos de singularização e do que aceitou das subjetividades que lhe foram reproduzidas. Diante disso, o papel do professor no ambiente escolar atual desvincula-se do historicamente construído. É necessário que esse seja problematizador, que crie situações favoráveis à contraposição de ideias, ao debate, à discussão e à produção de sínteses por parte de cada envolvido. Ao sujeito, cabe o processo de singularização, que pode ser favorecido pela escola, na medida em que essa é promotora de espaços de socialização. Nesse sentido, o professor exerce papel central. Ele pode ser o fio condutor para a transformação da instituição escola em local para discussão de subjetividades.

Para que estejam preparados, os professores precisam de formação, ação necessária para o desenvolvimento de uma escola mais crítica e reflexiva. Formação que proporcione reflexão, que permita (re)pensar, questionar práticas e crenças, e, acima de tudo, um ambiente que auxilie na criação de processos de singularização do professor.

Os professores precisam aprender na prática, por isso, a formação deve questionar os discursos dominantes e pôr em debate, trazer outras subjetividades, que são ideias de outros, de minorias, e assim, quem sabe, proporcionar outras interpretações. É certo que quem oferece e organiza um momento de reflexão docente está reproduzindo subjetividades, o que é inevitável, e o importante é não impor, mas criar um espaço de debate e de possibilitar outros discursos, que não os dominantes, trazendo outros pontos de vista.

Romper com as práticas limitadoras e manipuladoras da escola moderna não é uma tarefa simples, e o professor é o ator que pode iniciar esse avanço. Para isso, a formação de professores deve ser um espaço para discussões, possibilitando a (re)produção de outras subjetividades, desenhando um novo sentido ao fazer docente. O significado de escola precisa mudar, no dicionário, no entendimento da sociedade e, fundamentalmente, na prática.

\section{Políticas Recognitivas e Políticas Inventivas}

Para que a produção de novas subjetividades e até a singularização sejam possíveis, práticas inventivas são necessárias, pois, "aprender é experimentar incessantemente, é fugir ao controle da representação" (KASTRUP, 2008, p.107). No entanto, em geral, a escola tem formado a partir de práticas recognitivas.

As Políticas Recognitivas (PR) buscam a solução de problemas, tendo em vista que o sujeito e o mundo são constituídos de antemão e na construção de resultados, definem certo e errado, e trabalham com a representação. 
As Políticas Inventivas (PI) constroem problemas a partir de soluções dadas, o que promove o desmantelamento das formas usuais de perceber o mundo. A produção inventiva acontece quando ocorre o breakdown, que é uma experiência cognitiva não usual, a qual proporciona quebra, quando a memória não coincide com a percepção. "O mundo perturba, mas não informa. O conceito de "perturbação" ou de "breakdown" responde pelo momento da invenção de problemas, que é uma rachadura, um abalo, uma bifurcação no fluxo recognitivo habitual" (KASTRUP, 2005, p.1276). Esse momento de estranhamento provoca uma desubjetivação e assim uma nova subjetividade, que pode refletir num processo de singularização.

Para as PR a criatividade é habilidade muito importante a ser desenvolvida, pois tratase de encontrar novas soluções para problemas antigos, de diversas maneiras, com objetivos de economia, viabilidade, rapidez, etc. Enquanto as práticas recognitivas trabalham com a criatividade, as PI valorizam a invenção. A inventividade questiona o "normal", o "pronto", o não questionado, e as transforma em problemas, desnaturalizando, permitindo a singularização. "Além disso, a invenção é sempre invenção do novo, sendo dotada de uma imprevisibilidade que impede sua investigação e o tratamento no interior de um quadro de leis e princípios invariantes da cognição" (KASTRUP, 2005, p.1274).

Não significa que as PR são negativas, mas as PI também deveriam ser implementadas na escola, permitindo assim o desenvolvimento de habilidades diferentes e quem sabe a singularização a partir das práticas de problematização.

Kastrup (2005) explica que para as Políticas Recognitivas a aprendizagem é restringida a um processo de solução de problemas, os quais, muitas vezes, são propostos pelo próprio professor e limitam-se a formas prontas e à aquisição de informações.

No entanto, para as Políticas Inventivas, a aprendizagem surge como processo de invenção de problemas e "jamais é concluído e sempre abre para um novo aprendizado. Ele é contínuo e permanente, não se fechando numa solução e não se totalizando em sua atualização, precisando por isso ser sempre reativado" (KASTRUP, 2005, p.1280) Logo, o melhor aprendiz, e, assim, o melhor professor, não vivem por meio de hábitos cristalizados, mas estão sempre aprendendo. Por isso, a aprendizagem permanente poderia ser chamada, igualmente, de desaprendizagem permanente (KASTRUP, 2008).

A recognição é reproduzida, pois pensar desse modo foi e continua sendo ensinado. Kastrup (2005, p.1281) explica que "as práticas de aprendizagem inventiva constituem um caminho para expurgar o cognitivista que existe em nós e que nos habita, muitas vezes de maneira clandestina, assombrando-nos com o modelo da representação".

A aprendizagem não pode ser compreendida como uma simples passagem do não saber para o saber, nem de transição, nem de preparação, mas, "a aprendizagem é, sobretudo, invenção de problemas, é experiência de problematização" (KASTRUP, 2001, p.17). A experiência de recognição compreende uma síntese harmoniosa entre as faculdades, como quando sensação e memória chegam à mesma conclusão, que levam ao reconhecimento (KASTRUP, 2001). Já a experiência de problematização, de invenção, a sensibilidade, memória e imaginação agem de modo divergente. Quando surge estranhamento e tensão entre o conhecimento anterior ou a antiga 'verdade' e a experiência presente, emergem novas 'verdades'.

Por exemplo, de forma elucidativa, se uma pessoa tem o hábito de abrir a torneira para o lado direito, todas as torneiras de sua casa abrem para esse lado, e quando ela encontra uma torneira tem a sensação e memória de como abri-la e o faz, como sempre, sendo essa uma experiência de recognição. No entanto, se ela se depara com uma torneira que abre para a 
esquerda, isso causa estranhamento entre o saber de abrir a torneira anterior e a nova experiência que é diferente, formando, assim, uma experiência de problematização.

Uma experiência da problematização pode transformar experiências de recognição em novas oportunidades de problematização. Ou seja, a partir da aprendizagem, o que antes passava despercebido pode causar estranhamentos (KASTRUP, 2001).

As práticas da escola, em sua maioria, proporcionam experiências de recognição, pois não há muito espaço para questionamentos dos conhecimentos lá instituídos. Essas práticas se consolidaram devido às funções do contexto escolar, e, "embora modificadas, permanecem ainda hoje fortemente na escola, pois nem a escrita, nem os impressos e nem essa mentalidade escolar disciplinadora desapareceram: ainda são úteis à sociedade" (ROJO, 2017, p.7).

A cópia do quadro negro, exercícios de completar as lacunas, ditados, repetições, listas de exercícios de 'siga o exemplo', seminários, provas com questões fechadas que não exigem interpretação ou raciocínio lógico, mas apenas cópia, são práticas que remetem a experiências de recognição, as quais não dão oportunidades para que os estudantes tenham estranhamento. Muitas vezes o objetivo é completar o livro didático, e quando esse estiver completo isso não significará que o estudante terá aprendido. Além disso, o livro não traz todas as verdades. Por isso, a escola deve ofertar espaço para discutir o que acontece na vida do estudante, além do material escolar.

Atividades contextualizadas, que levem em conta a realidade do estudante, situaçõesproblemas, debates, tarefas que permitam o pensar e a interpretação, a produção escrita, oral, de arte ou de objetos de aprendizagem, possibilitam experiências inventivas. Quando o estudante está ativo no processo de ensino e aprendizagem, ele cria, e essa criação pode ser reprodução de subjetividade, mas pode ser espaço para a sua singularização, pois

\footnotetext{
Se considerarmos o que efetivamente se passa no campo da criação artística e científica, jamais encontraremos sistemas de centralização, instituições que controlem totalmente os processos criativos. De algum modo, as produções artísticas e científicas procedem de agenciamentos de enunciação que às vezes atravessam não só as instituições e as especialidades, mas também países e até épocas. Há sempre uma espécie de multicentragem dos pontos de singularização no campo da criação (GUATTARI; ROLNIK, 2010, p.36).
}

Práticas inventivas são necessárias para que, inseridos na sociedade da informação que está disponível de forma facilitada, principalmente diante do crescimento no uso da Tecnologia de Comunicação Digital, exista a possibilidade para desenvolver senso crítico.

Kastrup (2005) destaca que os estudantes de hoje estão assumindo características de dispersão, pois existe uma constante busca por novidades. Dispersão é falta de atenção, quando o foco vai mudando e passando por diferentes assuntos. De acordo com Coll e Monereo (2010), a rapidez é uma característica que define a sociedade da informação e afeta todos os seus processos e aspectos envolvidos. 
velocidade acelerada que convoca uma mudança constante do foco da atenção, em função dos apelos que se multiplicam sem cessar (KASTRUP, 2005, p.1282).

Habilitar os estudantes a lidar com a avalanche de informações disponíveis não é ensiná-los a lidar com as tecnologias, pois a troca do saber do professor pelas informações da internet continuará sendo transmissão, recognição; assim, é preciso ensiná-los caminhos para questionar.

O uso dos recursos tecnológicos pode ser muito rico, mas, para isso, é necessário utilizá-los para provocar o pensamento inventivo. É a partir da prática que se define o uso das tecnologias como recognitivas ou inventivas. As Tecnologias da Informação e Comunicação "não devem ser entendidas como meros objetos, tampouco como soluções para antigos problemas, mas como focos de criação de novos problemas, de novas relações com a informação, com o tempo, com o espaço, consigo mesmo e com o outro" (KASTRUP, 2008, p.99).

Rojo (2017) destaca que as tecnologias sempre estiveram a serviço das práticas sociais, e na escola esses recursos estão a favor de uma prática de transmissão de conhecimento, de um para muitos. Muitas vezes a tecnologia de ponta é utilizada, mas o processo de ensino e aprendizagem segue os mesmos moldes tradicionais.

Pois para ser mestre não basta transmitir informações novas, que logo serão substituídas por novas informações novas e igualmente descartáveis, mas produzir uma experiência nova, que não envelhece, que conserva sua força disruptiva e se mantém sempre nova (KASTRUP, 2005, p.1285).

Para usar das TCD a favor da aprendizagem, essas devem ser centrais na formação docente. Os momentos de reflexão docente, apesar de muitas vezes serem esperados, não devem ser um espaço para simples execução de receitas, isto é, a formação de professores precisa ser inventiva. Para isso, esses momentos também precisam possibilitar espaço para 'desaprender' e problematizar (DIAS, 2009).

Apenas as atitudes inventivas permitiram a (re)produção de outras subjetividades. E desenvolver a inventividade requer prática, pois, "embora a invenção não seja privilégio de grandes artistas ou cientistas, mas seja distribuída por todos e por cada um, ela depende de cultivo. A invenção não vai por si, mas envolve repetição" (KASTRUP, 2005, p.1279).

Logo, urge a necessidade da mudança nos cursos de formação de professores, momentos que ofereçam oportunidades para a reflexão e assim considerando a mudança de crenças e práticas, abram espaço para a invenção, para o crescimento humano da sociedade.

Conforme Kastrup (2005), Deleuze define que ao preparar a aula o professor está em processo de aprendizagem inventiva, e é na aula que o novo é experimentado, tendo lá a interação de muitos, todos únicos e diferentes, com liberdade para serem assim. "O desafio não é capturar a atenção do aluno para que ele aprenda, mas promover nosso próprio aprendizado da atenção às forças do presente, que trazem o novo em seu caráter disruptivo" (KASTRUP, 2005, p.1287).

O professor tem a missão de provocar experiências de problematização, possibilitar o estranhamento e a singularização dos estudantes, possibilitar outras, novas formas de pensar. Logo, para ser capaz de oferecer tais experiências aos seus estudantes, o professor deve possuir essas práticas. Estar sempre em aprendizagem inventiva e em processo de 
singularização é indispensável para que a prática docente faça a diferença e permita a diferença.

\section{Considerações Finais}

Para que a mudança da escola moderna aconteça existe um longo caminho com muitos desafios, e o presente estudo indica a formação de professores como um grande passo nessa direção, gerando momentos de reflexão docente, os quais devem buscar oferecer novas experiências para provocar o pensar, proporcionar breakdowns, questionar, problematizar. A formação escolar está fundamentada em práticas recognitivas, por isso já é hábito pensar na solução de problemas, no certo e errado, na verdade e na não verdade, e isso, na realidade, significa aceitar o que é dito pelo discurso. A singularização é um processo particular, mas só acontece quando as subjetividades são questionadas, práticas inventivas são utilizadas, permite-se refletir, e a percepção estranha a subjetividade dada. Assim, as Tecnologias de Comunicação Digital podem auxiliar a produzir esses momentos de práticas inventivas.

Guattari e Rolink (2010) explicam que só é possível desencadear processos de singularização em conexão com o exterior, assim a formação de professores é um momento ideal e de extrema importância para oportunizar tais reflexões. Logo, é necessário repensar e reconfigurar os cursos de formação e praticar o problematizar. Oferecer momentos de formação docente que provoquem estranhamentos, exijam sujeitos ativos, participativos desse processo, certamente produzirá muita resistência, porém, uma ação imprescindível. A partir da mudança das práticas docentes será possibilitado ao estudante ter também uma formação crítica, humana e singular necessária diante da fluidez e volatilidade da sociedade da informação, bem como frente às tecnologias e seu contínuo avanço.

\section{Referências}

CARRANO, Paulo César Rodrigues. Identidades Juvenis e Escola. Construção coletiva: contribuições à educação de jovens e adultos. Brasília: UNESCO, MEC, RAAAB, 2005. Disponível em:

http://portal.mec.gov.br/index.php?option=com_docman\&view=download\&alias=655vol3const-pdf\&Itemid=30192. Acesso em: ago. 2019.

CATAPAN, Araci Hack. Tertium: o novo modo do ser, do saber e do apreender:

Construindo uma Taxionomia para Mediação Pedagógica em Tecnologia de Comunicação Digital. 2001. Tese (Doutorado em Mídia e Conhecimento). Universidade Federal de Santa Catarina, Florianópolis, SC, 2001.

COLL, César; MONEREO, Carles. Educação e aprendizagem no século XXI: novas ferramentas, novos cenários, novas finalidades. In: COLL, Cesar; MONEREO, Carles.

Psicologia da educação virtual: aprender e ensinar com as tecnologias da informação e da comunicação. Porto Alegre: Artmed, 2010. Disponível em:

http://srvd.grupoa.com.br/uploads/imagensExtra/legado/C/COLL_Cesar/Psicologia_da_Educ acao_UniA/Lib/Amostra.pdf Acesso em: ago. 2019

CORAZZA, Sandra. O docente da diferença. In: Revista Periferia/FEBF, Rio de Janeiro, v.1, n. 1, p.91 - 110, 2008. Disponível em: http://www.epublicacoes. uerj.br/index.php/periferia/article/download/3422/2348. Acesso em: ago. 2019. 
Revista de Educação, Ciência e Tecnologia

DIAS, Rosimeri de Oliveira. Formação Inventiva de Professores e Políticas de Cognição. In: INFORMÁTICA NA EDUCAÇÃÕ: teoria \& prática Porto Alegre, v.12, n.2, jul./dez. 2009. Disponível em: https://seer.ufrgs.br/InfEducTeoriaPratica/article/view/9313 Acesso em: ago. 2019.

FOUCAULT, Michel. Em defesa da sociedade. São Paulo, Martins Fontes, 1999.

FOUCAULT, Michel. Vigiar e Punir: história da violência nas prisões. Petrópolis, RJ: Vozes, 2009.

GUATTARI, Félix. ROLNIK, Suely. Micropolítica: cartografias do desejo. Petrópolis, RJ: Vozes, 2010.

KASTRUP, Virgínia. Aprendizagem, arte e invenção. Psicologia em Estudo, Maringá, v. 6, n. 1, p. 17-27, jan./jun. 2001. Disponível em: http://www.scielo.br/pdf/pe/v6n1/v6n1a03.pdf Acesso em: ago. 2019.

KASTRUP, Virgínia. Políticas Cognitivas na formação do professor e o problema do devirmestre. Educação e Sociedade, Campinas, vol. 26, n. 93, p. 1273-1288, Set./Dez. 2005. Disponível em: http://www.scielo.br/pdf/es/v26n93/27279.pdf. Acesso em: ago. 2019.

KASTRUP, Virgínia. A cognição contemporânea e a aprendizagem cognitiva. In: Políticas da cognição. Kastrup.V.; Tedesco, S.; Passos, E. Porto Alegre: Sulina, 2008.

MASCARENHAS, Leonardo Balbino. Biopolítica, Educação e Resistência na Contemporaneidade. Educação \& Realidade, Porto Alegre, v. 43, n. 4, p. 1537-1554, out./dez. 2018. Disponível em: http://www.scielo.br/pdf/edreal/v43n4/2175-6236-edreal2175-623675587.pdf. Acesso em: ago. 2019.

ROJO, Roxane. Entre Plataformas, ODAS e Protótipos: Novos Multiletramentos em Tempos de WEB2. The ESPecialist: Descrição, Ensino e Aprendizagem, v. 38, n. 1, jan-jul 2017. Disponível em: https://revistas.pucsp.br/index.php/esp/article/view/32219 Acesso em: ago. 2019.

ZAMBEL, Luciana.; LASTÓRIA, Luiz Antônio Nabuco. Educação e emancipação em T. W. Adorno: contribuições para a formação de professores. Revista Ibero-Americana de Estudos em Educação, Araraquara, v. 11, n. 4, p. 2205-2218, 2016. Disponível em: <http://dx.doi.org/10.21723/riaee.v11.n4.8794>. Acesso em: jul. 2019.

Recebido em agosto de 2019.

Aprovado em outubro de 2019. 